\title{
Modelos e diretrizes para uma educação inclusiva: revisão de literatura
}

\author{
Maria das Graças Soares Siqueira* \\ Fernanda Aguillera**
}

\section{Resumo}

Apesar da inclusão escolar ser uma realidade na legislação brasileira, verifica-se, no cotidiano das instituições de ensino regular, particulares e públicas, certa dificuldade em lidar com a adequação às demandas dos alunos especiais. Assim, o objetivo desse trabalho foi identificar pesquisas contendo diretrizes e modelos para promoção da inclusão escolar, que abarcassem a ação do psicólogo. Para tanto, realizou-se busca sistemática nas bases de dados da Biblioteca Virtual em Saúde (BVS-Psi), especificamente Lilacs, Scielo e Pepsic. Utilizando-se a palavra-chave inclusão escolar, obteve-se 390, 39 e 22 artigos, respectivamente. Como um número considerável de títulos fugia ao objetivo do trabalho, optou-se por restringir a busca com as palavras-chaves intervenção e inclusão escolar, resultando um total de 55 artigos. A partir da leitura de seus títulos e resumos, foram excluídos os trabalhos com temática em desacordo aos interesses da pesquisa (31) e em duplicidade (09), totalizando 15 artigos para análise. Como resultado, verificou-se que de 2005 para cá houve uma crescente produção de trabalhos interventivos voltados para educaçáo inclusiva, predominantemente na área da Psicologia, porém mais publicados em revistas de Educação Especial ou de Educação. Em sua maioria, dedicaram-se a um público etário de 04 a 16 anos, e as intervençôes foram mais direcionadas a deficiências específicas ou não identificadas. Mas são raros os relatos de procedimentos e recomendaçôes mais abrangentes, que sirvam de norteadores à prática nesse campo. Tais resultados sugerem lacunas na produção científica, voltadas à apresentação de modelos inclusivos mais amplos, com a participação do psicólogo.

Palavras-chave: Inclusão escolar; Intervenção; Psicologia.

\footnotetext{
* Graduada em Ciências Biológicas (UFS), especialização em Psicomotricidade e Psicopedagogia, Concludente curso Psicologia(Faculdade Pio Décimo), Aracaju, Sergipe, Brasil.

** Professora doutora da Faculdade de Administraçấo e Negócios de Sergipe, Aracaju, Sergipe, Brasil.
} 


\section{Templates and guidelines for an inclusive education: literature review}

\section{Abstract}

Despite school inclusion being a reality in Brazilian legislation, the fact that regular teaching institutions, being them private or public, have some difficulties in dealing with the adequacy of special students demands can still be perceived. Thus, the aim of this work was to identify researches containing guidelines and models to promote school inclusion, covering, also, psycologists' actions. To do so, we performed a systematic search at the Biblioteca Virtual em Saúde - BVS-Psi (Virtual Health Library), specifically Lilacs, Scielo and Pepsic. By using the keyword "school inclusion", we were able to obtain 390, 39 and 22 papers, respectively. As a considerable number of titles didn't meet our objective, we decided to restrict the search with the keywords "intervenction" and "school inclusion", resulting in a total of 55 papers. Upon the reading of their titles and abstracts, we excluded those whose theme did not meet our research's interest (31) and in duplicity, resulting in 15 works to analyze. As a result, it was found that, since 2005, there has been a growth in interventional studies related to inclusive education, predominantly at the Psychology field, although they have been published, mostly, by Special Education and Education journals. Most of these papers were dedicated to an age public of 04 to 16 years, and their interventions were more targeted to specific or non-identified disabilities. Are rare, though, the reports of procedures and more in-depth recommendations that could be used as a guide to the practice at this field. These results suggest gaps in the scientific production, aimed at presenting broader inclusive models with the psychologist participation.

Keywords: School inclusion; Intervention; Psychology.

\section{Introdução}

A educação inclusiva, que é um"paradigma educacional fundamentado na concepção de direitos humanose propóe a ideia de igualdade, no sentido de eliminar as circunstâncias de exclusãono interior da escola", é hoje uma realidade nas leis civis e educacionais do Brasil. Tal situação pode ser observada na Constituição Federal, na Lei de Diretrizes e Bases da Educação Nacional (9394/96), no ECA (8.069/90) e nas várias políticas de atendimento à pessoa com deficiência propostas pelo governo federal.

Verifica-se, portanto, um avanço social nessas leis, principalmente se tivermos o conhecimento histórico de como foi a Educação Especial no Brasil. Fruto disso, nota-se uma crescente demanda de atendimento a alunos com necessidades educativas especiais (NEE) nas escolas regulares que, desde 1996, são orientadas a recebê-los.

O Censo Escolar/INEP/MEC (2006) comprova tal situação, onde se observa, com relação à educação especial, uma evolução nas matrículas, passando de 43.923 alunos em 1998 para 325.316 em 2006. Fica claro que, essa crescente demanda, 
amparada por todo um arcabouço legislativo, tornou-se para a escola uma realidade diferenciada daquela que costumeiramente atendia, e isso escancara uma outra realidade - o não saber agir, o não saber fazer frente às dificuldades que se apresentam no caso a caso de cada aluno especial (MACHADO; ALMEIDA, 2010, p. 01).

No entanto, percebe-se que os professores, apesar de suas formaçóes específicas, seja na forma de cursos de curta duração ou até em nível de especialização, ainda carecem de um modelo prático, interventivo, que oriente a lida com alunos das diversas NEE incluídas no ambiente escolar. O que fazer? Como trabalhar com o aluno autista ou com Síndrome de Down, por exemplo? Como adaptar currículo, avaliaçôes, ambientes para receber de modo inclusivo essas crianças? Como diagnosticar o aluno que chega à escola com necessidades diferenciadas, mas ainda não identificadas pela família? Tais indagaçôes tornam notória a discrepância entre o exigido por lei e a realidade escolar, salientando que, no Brasil, temos leis de primeiro mundo, mas cuja aplicabilidade ainda evidencia abismos (LOPES, 2014, p. 743).

No que tange à produção científica acerca de intervenções com foco na inclusão escolar, nota-se a publicação de diversos estudos e relatos de experiência, mas, em geral, direcionados a uma única deficiência, como autismo (LEMOS; SALOMÁO; RAMOS,2014 e GOMES, 2007), deficiência mental (JURDI; AMIRALIAN, 2006), Síndrome de Down(FREITAS; MENDES, 2008), por exemplo. Outros se direcionam a intervençóes com os pais (ROLFSEN; MARTINEZ, 2008), com professores (FERREIRA et al, 2009; SILVA; MENDES, 2012;CRUZ et al, 2011; OMOTE et al, 2005; SOUZA; PICH, 2013)ou até a reflexóes acerca do processo inclusivo. Todavia, indagamos: essas produçóes atendem às demandas práticas das escolas, quando confrontam-se com os diversos casos que surgem sob a terminologia NEE-Necessidades Educativas Especiais?

Tentando responder a essa lacuna, buscou-se, por meio de uma revisão de literatura, identificar trabalhos que relatem intervençôes com foco na educação inclusiva, verificando, especialmente, possíveis contribuiçôes do profissional psicólogo. Inicialmente, a proposta foi caracterizar essa produção científica em relação a variáveis como: período de publicação e tipo de pesquisa, áreas do conhecimento em que foram produzidos e publicados os estudos, público-alvo, pessoas e profissionais envolvidos nas intervençóes, se propostas no contexto de escolas públicas ou particulares e em quais níveis de ensino. Em seguida, pretendia-se sistematizar informaçóes sobre modelos e diretrizes para intervenção nesse campo, já devidamente implantados e avaliados, que viessem a servir de norteador à prática profissional do psicólogo nas escolas.

\section{A educação inclusiva no Brasil}

Entendemos que, para uma melhor elucidação acerca das justificativas ora apresentadas, torna-se necessário conhecermos o processo histórico da prática inclusiva cujo termo inclusão aparece pela primeira vez, oficialmente, no Relatório Warnock (1978), "englobando não só alunos com deficiências, mas todos aqueles que, ao longo do seu percurso escolar, possam apresentar dificuldades específicas de aprendizagem". 
(LOPES, 2014, p. 743). Entretanto, é com a Declaração de Salamanca (1994) que o termo ganhou força e "definiu a necessidade de se atuar de modo a conseguir escolas para todos", de forma integrada e na rede regular de ensino. Tal documento responsabilizou a todos os países participantes pela implementação de uma política de educaçáo mais inclusiva e extensiva a todos.

Verifica-se, portanto, que para uma melhor compreensão da inclusão proposta em Salamanca faz-se necessário definirmos as diferenças entre esta, a educação especial proposta até a década de 80 e a educação especial na perspectiva da educação inclusiva. Assim, Noronha e Pinto (2008) citam que:

No final do século XVIII e início do século XIX inicia-se o período da institucionalização especializada de pessoas com deficiências, e é a partir de então que podemos considerar ter surgido a Educaçáo Especial. Essa Educação acontecia em escolas fora das povoaçóes, argumentando que o campo lhes proporcionaria uma vida mais saudável e alegre. Desta maneira se tranquiliza a consciência coletiva, pois estava a proporcionar cuidado e assistência para quem necessitava, protegendo o deficiente da sociedade sem que esta tivesse de suportar o seu contato. (NORONHA; PINTO, 2008, p.01).

Nota-se que nesse período havia uma preocupação com a integração, ou seja, preparar primeiro para em seguida, se aptos, integrar na sociedade e/ou escolas. Era a Educação Especial com foco na integração.

Já em meados da década de 90 com as discussôes acerca da inclusão escolar, esse conceito de educação especial começa a ser discutido na perspectiva da educação inclusiva e, segundo Noronha e Pinto (2008), a Educação Especial passa a se ocupar do:

[...] atendimento e da educação de pessoas com deficiência e transtornos globais de desenvolvimento em instituiçóes especializadas. É organizada para atender específica e exclusivamente alunos com determinadas necessidades especiais. Onde profissionais especializados como educador físico, professor, psicólogo, fisioterapeuta, fonoaudiólogo e terapeuta ocupacional trabalham e atuam para garantir tal atendimento. (NORONHA; PINTO, 2008, p. 03).

Verifica-se, portanto, que, embora receba esse atendimento especializado, o aluno está inserido na rede regular de ensino, e portanto, incluído. Assim, Noronha e Pinto (2008) definem Educaçáo Inclusiva como:

[...] um processo em que se amplia à participação de todos os estudantes nos estabelecimentos de ensino regular. Trata-se de uma reestruturação da cultura, da prática e das políticas vivenciadas nas escolas de modo que estas respondam à diversidade de alunos. É uma abordagem humanística, democrática que percebe o sujeito e suas singularidades tendo como objetivos o crescimento, a satisfação pessoal e a inserção social de todos. (NORONHA; PINTO, 2008, p. 03). 
Considerando que as mudanças sociais ocorridas nesse período foram acompanhadas do surgimento de leis que deram amparo e tornaram necessárias essas práticas inclusivas, constata-se que a Constituição de 1988, considerada uma constituição cidadâ, foi fundamental para o surgimento de outras leis dentro dessa perspectiva inclusiva, a saber:

- Lei n. 8069 de 13 de julho de 1990 (ECA-Estatuto da Criança e do Adolescente), cujo artigo 53 dispóe sobre a "igualdade de condiçóes para acesso e permanência, além de atendimento educacional especializado aos portadores de deficiência na rede regular, preferencialmente".

- LDB - Lei de Diretrizes e Bases da Educação Nacional (9394/1996), onde a Educação Especial aparece enquanto modalidade de ensino, sendo normatizado que todos os alunos com necessidades educativas especiais precisam ser atendidos nas escolas regulares (artigo V).

- Lei 10.436/02, que reconhece a Língua Brasileira de Sinais como meio legal de comunicação e expressão da Linguagem de Sinais-Libras, além dos diversos decretos que amparam os indivíduos com necessidades especiais.

Verifica-se, portanto, que apesar de todo um corpo legislativo que vem se delineando a partir da década de 90 no Brasil, com vistas a amparar as pessoas com necessidades educativas especiais, uma série de incongruências na relação teórico prática do termo Inclusão Escolar é percebida. A começar com a preocupação dos governos e administradores da educação que, conforme citado por Rocha (2008):

[...] apresentam como prioridade a ampliação de vagas para acolher o maior número possível de alunos destinando uma preocupação secundária com a formação do professor para lidar com a diversidade, cujas saídas implementadas têm sido variadas, desde supervisões esporádicas à distribuição de material didático ao professor. (ROCHA, 2008).

Ora, a afirmativa de Rocha (2008) é cotidianamente observada no dia a dia das escolas, razão pela qual a elaboração dessa pesquisa se justifica, ao mesmo tempo em que, para atender a essas demandas diferenciadas no seio das instituições de educação, a presença do psicólogo parece tornar-se necessária. Todavia, esse profissional traz a busca de superaçáo dos desafios frente à própria formação, quando confrontase no atendimento dessas demandas tão peculiares. Tal afirmativa é compartilhada por Mattos e Nuernberg (2010), quando citam que:

\footnotetext{
"a psicologia como ciência e profissão muito ainda pode contribuir para pensar estratégias outras de atenção e atendimento dos alunos com deficiência nos diferentes níveis de ensino, engendrando ações mais focadas nas instituições escolares e em seus processos interativos, superando enfoques individualistas e restritos ao modelo médico da deficiência”. (OLKIN; PLEDGER, 2003 apud MATTOS e NUERNBERG, 2010, p. 3).
} 
Atualmente se confunde muito com a terminologia utilizada para as crianças especiais que serão incluídas nas escolas regulares e, para melhor esclarecimento acerca disso, usaremos nesse trabalho o termo Necessidades Educativas Especiais (NEE).

Assim, a partir de um recorte temporal considerando a primeira LDB (1961), percebe-se que as crianças-alvo eram denominadas de excepcionais, já a Lei n. 5.692/71 vai ampliar esse grupo quando considera aqueles com atraso na idade e superdotados (LOPES, 2014, p. 741).

Fica notória a substituição do termo excepcional por Necessidades Educativas Especiais, que começa a ser utilizado a partir de 1990 com a Declaração de Salamanca e, também, na nossa atual LDB (Lei 9394/96). Todavia, percebe-se mais uma mudança nessa terminologia a ser observada na Lei $12.796 / 13$, que traz no seu bojo o termo "educandos com deficiência, transtornos globais do desenvolvimento e altas habilidades ou superdotação", para substituição do termo genérico de alunos com Necessidade Educativas Especiais. Essa lei procura delimitar mais as crianças-alvo desses atendimentos no interior da escola (LOPES, 2014, p. 748).

Considerando, portanto, o histórico da Educação Inclusiva no Brasil, percebe-se avanços, não só na denominação dos atendidos, mas especialmente nos direitos destes dentro do ambiente escolar. Essa realidade sugere a necessidade de produçáo científica voltada para a oferta de modelos que direcionem de modo mais concreto a lida com essas demandas. E foi esse fato que motivou o presente trabalho: a busca de publicaçôes científicas que apresentassem tais modelos. Para tanto, realizou-se levantamento bibliográfico cujos procedimentos serão pormenorizados no método dessa pesquisa.

\section{Método}

Esse trabalho trata-se de pesquisa cujo caráter foi exploratório e descritivo, considerando a abordagem bibliométrica. Para tanto, procurou-se identificar os trabalhos interventivos com foco na educação inclusiva, considerando as contribuiçôes do profissional psicólogo.

A coleta de dados se deu com a utilização de artigos cuja busca inicial foi espontânea nas bases de dados Lilacs, Scielo e Pepsic, utilizando-se a palavra-chave Inclusão Escolar, que resultou em 390, 39 e 22 artigos, respectivamente. Verificando-se um número considerável de títulos cuja temática fugia ao objetivo do trabalho, nova busca foi realizada e pautou-se na combinação das palavras-chave intervenção e inclusão escolar. Nessa segunda busca, utilizou-se como fonte de pesquisa a BVS-Psi, tendo sido selecionadas as mesmas bases de dados já consultadas. A consulta sistemática foi realizada em 29 de março de 2014 e resultou em 32, 17 e 06 artigos, nas bases Lilacs, Scielo e Pepsic, respectivamente.

Considerou-se como critérios de inclusão os artigos em português, que tratavam de intervençóes em favor da inclusão escolar, com contribuiçôes da psicologia. A partir da leitura dos títulos e resumos encontrados, foram excluídos os trabalhos com temática em desacordo aos interesses da pesquisa (31) e em duplicidade (09), 
permanecendo um total de 15 artigos selecionados para análise. Os referidos artigos foram lidos na íntegra e fichados de modo sistemático, de acordo com as variáveis de interesse. Em seguida, os dados passaram por análise estatística descritiva, sendo organizados em tabelas de frequência.

\section{Resultados e discussão}

Os resultados obtidos da análise dos 15 artigos acerca das intervençóes no processo de inclusão escolar foram classificados em três grandes categorias considerando as seguintes variáveis: 1.Caracterizaçáo dos estudos segundo período de publicação, tipos de estudos, área do conhecimento e periódicos de origem (Tabelas 1 e 2); Caracterização do público alvo das intervençôes segundo gênero, faixa etária, pessoas envolvidas e deficiências atendidas (Tabela 3); Caracterização dos estudos segundo a região do país, ambiente alvo e nível educacional dos participantes (Tabelas 4 e 5).

A Tabela 1 apresenta o período de publicação dos trabalhos analisados.

\begin{tabular}{c|c|c}
\hline PERÍODO (ANO) & Freq. Absoluta & Freq. Relativa (\%) \\
\hline $2005-2007$ & 3 & 20 \\
\hline $2008-2010$ & 6 & 40 \\
\hline $2011-2014$ & 6 & 40 \\
\hline Total: & $\mathbf{1 5}$ & $\mathbf{1 0 0}$ \\
\hline TIPOS DE ESTUDO & Freq. Absoluta & Freq. Relativa (\%) \\
\hline Qualitativo & 8 & 53,3 \\
\hline Quali-quantitativo & 7 & 46,7 \\
\hline Quantitativo & - & $\mathbf{1 0 0}$ \\
\hline Total: & $\mathbf{1 5}$ &
\end{tabular}

A Tabela 1 revela que as publicaçóes iniciaram-se em 2005, havendo a publicação de apenas 3 trabalhos no período de 2005 a 2007 (20\%). Observa-se um aquecimento na produção científica sobre o tema nos períodos seguintes, com a publicação de 6 trabalhos por período (40\%). Destacaram-se em volume de publicaçóes os anos de 2010 (03 artigos), 2013 (02 artigos), 2011( 02 artigos) e 2008 (02 artigos). Nota-se, portanto, que a temática em questão tem sido, possivelmente, uma demanda social relevante em nossos tempos.

Já no tocante a variável tipos de estudos, foram verificadas as abordagens adotadas nas pesquisas como qualitativas, quantitativas e quali-quantitativas. Observa-se que os trabalhos analisados foram qualitativos $(53,3 \%)$ ou quali-quantitativos (46,7\%), envolvendo reduzido número de participantes. Trabalhos somente quantitativos não foram observados dentre as pesquisas analisadas. 
A Tabela 2 retrata as áreas do conhecimento e os periódicos que cederam espaço à publicação dos trabalhos analisados.

Quanto à área do conhecimento, observa-se, na Tabela 2, que a Psicologia foi a que mais cedeu espaço a realização de práticas em favor da inclusão escolar $(40 \%)$, seguida da Educação Especial com 26,6\% e da Psicopedagogia com 20\%. Isso pode revelar indícios de que o profissional psicólogo está amadurecendo uma ação frente a essas demandas, que são crescentes no ambiente escolar, conforme o Censo Escolar/ INEP/MEC (2006).

Tabela 2 - Área do conhecimento e periódicos de origem dos trabalhos analisados.

\begin{tabular}{l|l|l}
\hline ÁREA & Freq. Absoluta & Freq. Relativa (\%) \\
\hline Psicologia & 6 & 40 \\
\hline Educaçáo Especial & 4 & 26,60 \\
\hline Psicopedagogia & 3 & 20 \\
\hline Educação & 1 & 6,70 \\
\hline Saúde & 1 & 6,70 \\
\hline Total & $\mathbf{1 5}$ & $\mathbf{1 0 0}$ \\
\hline PERIÓDICOS & Freq. Absoluta & Freq. Relativa (\%) \\
\hline Revista Brasileira de Educação Especial & 4 & 26,70 \\
\hline Paideia & 2 & 13,30 \\
\hline Temas Psicologia (online) & 1 & 6,70 \\
\hline Revista Psicopedagogia & 1 & 6,70 \\
\hline Construção Psicopedagógica & 1 & 6,70 \\
\hline Caderno Psicopedagogia & 1 & 6,70 \\
\hline Revista Fractal Psicologia & 1 & 6,70 \\
\hline Estudos de Psicologia (Campinas) & 1 & 6,70 \\
\hline Revista Educação & 1 & 6,70 \\
\hline Ciência Saúde Coletiva & 1 & 6,70 \\
\hline Revista Movimento & 1 & 6,70 \\
\hline Total: & $\mathbf{1 5}$ & $\mathbf{1 0 0}$ \\
\hline
\end{tabular}

Ainda na Tabela 2, detalha-se os periódicos que publicaram os trabalhos analisados. As revistas que mais publicaram foi a Revista Brasileira de Educação Especial $(26,7 \%)$ e a Revista Paideia (13,3\%); as demais (09 revistas) tiveram apenas um artigo publicado (6,7\%). Isso sugere que essa temática tem sido mais agregada a periódicos específicos da Educação Especial e num segundo plano aos de Psicologia (Paideia-Ribeirão Preto). Tal informação suscita, possivelmente, uma necessidade de que essa temática possa ser mais veiculada em periódicos voltados para a Psicologia, uma vez que as demandas de Educação Especial com foco na intervenção têm sido uma realidade para o profissional psicólogo e, por isso, a necessidade de Informação é premente. 
Os dados pertinentes à caracterização do público alvo das intervençóes segundo gênero, faixa etária, pessoas envolvidas e deficiências atendidas podem ser observados na Tabela 3 .

Tabela 3 - Caracterizaçăo do público alvo das intervençōes segundo gênero, faixa etária, pessoas envolvidas e deficiências atendidas.

\begin{tabular}{l|l|l|l}
\hline \multicolumn{2}{l|}{ VARIÁVEIS } & Freq. Absoluta & Freq. Relativa (\%) \\
\hline \multirow{4}{*}{ Gênero } & Ambos os sexos & 10 & 66,7 \\
\cline { 2 - 4 } & Feminino & 5 & 33,3 \\
\cline { 2 - 4 } & Masculino & - & - \\
\hline \multirow{2}{*}{ Total: } & Acima de 16 anos & 6 & $\mathbf{1 0 0}$ \\
\hline & $12-16$ & 15 & 40 \\
\cline { 2 - 4 } & $8-12$ & 3 & 6,7 \\
\cline { 2 - 4 } & $4-8$ & 3 & 20 \\
\cline { 2 - 4 } & Não informado & 2 & 20 \\
\hline Total: & & $\mathbf{1 5}$ & 13,3 \\
\hline PESSOAS ENVOLVIDAS & Freq. Absoluta & Freq. Relativa (\%) \\
\hline Pessoas com deficiência & 5 & 33,3 \\
\hline Professores & 4 & 26,7 \\
\hline Alunos/ Colegas & 2 & 13,3 \\
\hline
\end{tabular}

Esses dados nos permitiram conhecer com mais profundidade os participantes das pesquisas analisadas. Assim, verifica-se que, na maioria das pesquisas analisadas, não faz distinção de gênero, atendendo a públicos de ambos os sexos $(66,7 \%)$, apesar de 5 estudos terem se voltado ao público feminino (33,3\%). Isso mostra que as intervençóes se deram, na maioria das vezes, trabalhando indistintamente em relação ao gênero, tanto no que se refere a alunos, quanto a professores.

Já na variável faixa etária, observou-se que a maioria das intervençôes atuou com um público cuja idade está acima de 16 anos (40\%), envolvendo professores e familiares nesses casos, e que as idades de 4 a 8 e 8 a 12 anos apresentam-se em incidência similar (20\% cada). Porém, se somarmos os intervalos de 4 a 8 anos $(20 \%), 8$ a $12 \operatorname{anos}(20 \%)$ e 12 a 16 anos (6,7\%), mais característicos do alunado, verifica-se que passam a ser maioria $(46,7 \%)$. Tais dados sugerem, então, que os públicos das intervençóes podem estar, em sua maioria, nas faixas etárias de 4 a 16 anos, portanto, com alunos da Educação Infantil ao Ensino Fundamental Maior (9o Ano).

Ainda na Tabela 3, pode-se observar que as pessoas envolvidas nas intervençôes foram pessoas com deficiência, alunos com NEE e seus colegas, professores, familiares e psicólogos. Tais resultados mostram que as intervençôes foram, em sua maioria, muito específicas a uma deficiência (Autismo, Síndrome de Down, Paralisia cerebral ou Deficiência Mental), ou não foram especificadas (66,6\%). 
A análise dessa variável parece deixar uma lacuna da necessidade de um projeto interventivo mais amplo, que dê conta de atender às várias necessidades educativas especiais que chegam às escolas. Possivelmente um projeto com modelos e diretrizes para o atendimento às crianças com NEE que anualmente matriculam-se nas escolas brasileiras. No trabalho de Fabricio e Cantos (2011), encontramos uma reflexão acerca da postura diagnóstica como instrumento de trabalho da escola, sugerindo a parceria contínua dos profissionais de Educação e da Saúde, em suas diversas especialidades, para lidar com as dificuldades de aprendizagem que se apresentam no cotidiano escolar. Segundo esses autores, "as escolas se vêem diante da necessidade de incluir o aluno que não se adapta ao padrão linear da ensinagem”. Assim, as escolas precisam desenvolver um projeto pedagógico que atinja a todos, atendendo-se a todas as necessidades educativas especiais.

Para tanto, é citado no trabalho de Fabricio e Cantos (2011) que

$$
\begin{aligned}
& \text { “a intervenção precisa ter um caráter multidisciplinar(objetivos e es- } \\
& \text { tratégias comuns com avaliaçáo dos efeitos), processual(seguir um } \\
& \text { padrão de planejar/desenvolver/avaliar/replanejar) e singular(espe- } \\
& \text { cífico para cada um)". (FABRICIO; CANTOS,2011, p. } 5 \text { e 6). }
\end{aligned}
$$

A Tabela 4 apresenta a caracterização dos estudos segundo a região do país e o ambiente onde ocorreram as intervençôes.

Tabela 04 - Localização geográfica e por ambiente social dos trabalhos.

\begin{tabular}{c|c|c}
\hline REGIÁO & Freq. Absoluta & Freq. Relativa (\%) \\
\hline Sudeste & 12 & 80 \\
\hline Sul & 1 & 6,7 \\
\hline Nordeste & 1 & 6,7 \\
\hline Centro-Oeste & 1 & 6,7 \\
\hline Total & $\mathbf{1 5}$ & $\mathbf{1 0 0}$ \\
\hline AMBIENTE ALVO & Freq. Absoluta & Freq. Relativa (\%) \\
\hline Escola pública & 11 & 73,3 \\
\hline Náo citado & 2 & 6,7 \\
\hline Escola privada & 1 & 6,7 \\
\hline Creche pública & 1 & $\mathbf{1 0 0}$
\end{tabular}

Os resultados mostram que a região sudeste lidera como a maior produtora de trabalhos com a temática estudada (80\%), seguida pelas regiôes Sul, Nordeste e Centro-Oeste, que publicaram apenas um trabalho $(6,7 \%)$. O sudeste é notadamente uma regiáo que se destaca na produção científica nacional, em diversas áreas. No que se refere à área em questão, cabe destacar o Programa de Pós-Graduação em Educação Especial da UFSCar, no interior paulista, reconhecido polo de excelência na formação de professores e pesquisadores. Isso talvez justifique a predominância de 
publicaçôes na região. No mesmo padrão, no entanto, a região sul surpreendeu pela escassez de trabalhos dedicados à prática da educaçáo inclusiva, dado que concentra instituiçôes de ensino superior dedicadas à formação especializada em Educação Especial, em nível de graduação e pós-graduação.

Quanto aos espaços nos quais se deram as intervençóes, verificou-se que a maioria dos trabalhos analisados foram realizados em Escolas Públicas $(73,3 \%)$, ou trataram-se de trabalhos focando reflexôes acerca da temática, sem deixar claro um público e local específico (13,3\%). Os demais locais identificados foram creche pública e escola privada $(6,7 \%)$. Os resultados sugerem que a rede privada de ensino ainda carece de trabalhos interventivos que sejam norteados e avaliados por métodos científicos, especialmente com contribuiçôes do psicólogo. Além disso, cabe questionar os motivos da escolha dos pesquisadores pela rede pública: maior facilidade ou maior demanda? Vale considerar que, por um lado, há a responsabilidade e o compromisso das instituiçóes públicas de pesquisa se dedicarem ao ensino público, notadamente carente de recursos e iniciativas governamentais. Por outro, a rede privada nem sempre se coloca disponível para trabalhos dessa natureza, que sejam ainda experimentais ou avaliativos, ora por restriçóes da parte da clientela, ora pelo receio das implicaçóes de seus resultados no negócio. Seja qual for o caso, perde-se a chance de aprender com as pesquisas, aprimorar o atendimento e/ou de disseminar boas práticas. Tabela 5.

O nível educacional dos sujeitos-alvo das intervenções pode ser observado na

Tabela 05- Nível Educacional do público-alvo das intervençôes .

\begin{tabular}{c|c|c}
\hline NÍVEL EDUCACIONAL & Freq. Absoluta & Freq. Relativa \\
\hline Ens. Fundamental I e II & 4 & 26,7 \\
\hline Ensino Superior & 3 & 20 \\
\hline Ed. Infantil & 2 & 13,3 \\
\hline Ensino Médio & 1 & 6,7 \\
\hline Diversos & 2 & 13,3 \\
\hline Não citado & 3 & 20 \\
\hline Total & $\mathbf{1 5}$ & $\mathbf{1 0 0}$ \\
\hline
\end{tabular}

Observa-se que a maioria pertence ao Ensino Fundamental (26,7\%) e Ensino Superior (20\%, no caso professores). A Educação Infantil e o Ensino Médio foram alvo de apenas $13,3 \%$ e $6,7 \%$ dos estudos, respectivamente. Os casos em que não foram citados os níveis educacionais referem-se aos trabalhos de reflexão acerca da temática (20\% ). Já como "Diversos", foram classificados os estudos que envolvem professores e alunos (13,3\%). Ficou evidente a carência de trabalhos dessa natureza junto ao ensino médio, já que as tecnologias de ensino têm avançado e, com elas, a formação escolar das pessoas com necessidades educativas especiais. 
Os resultados, ora expostos, parecem deixar evidente a necessidade de trabalhos interventivos voltados para uma atuação mais ampliada no atendimento dos alunos com NEE; se a escola recebe concomitantemente alunos com diversas necessidades especiais. Intervençôes pontuais como o atendimento a deficiências específicas encontradas nos trabalhos que pontuaram sobre autismo (LEMOS; SALOMÃO, N; RAMOS, 2014 e GOMES, 2007), a deficiência mental (JURDI; AMIRALIAN, 2006) e a Síndrome de Down (FREITAS; MENDES, 2008), por exemplo, são contribuiçôes importantes que ilustram o atendimento a essas especialidades, embora retratem açốes mais individualizadas. Mas a necessidade atual parece ser de um projeto de intervenção que englobe a diversidade e inclusive os pais (ROLFSEN; MARTINEZ, 2008) e professores (FERREIRA et al, 2009; SILVA; MENDES, 2012; CRUZ et al, 2011; OMOTE et al, 2005; SOUZA; PICH, 2013). Entendemos que, por tratar-se de uma multiplicidade de necessidades especiais, a atuação de uma equipe multiprofissional é necessária, mas tendo no Psicólogo um foco norteador dos procedimentos, sem deixar de considerar a importância das diversas áreas que também podem contribuir com seus saberes.

\section{Conclusões}

De modo geral, os resultados dessa pesquisa apontam que a produção de trabalhos dedicados a intervenções no âmbito da Educação Inclusiva vem crescendo a partir de 2005, sendo mais notória a partir de 2010. Possivelmente, cresce em paralelo a uma demanda que também aumenta no ambiente escolar, fruto da legislação que versa sobre a temática e busca garantir o atendimento aos alunos com necessidades educativas especiais na escola regular.

Mesmo os estudos sendo direcionados a intervençóes na área da Psicologia, foi notável a publicação dos mesmos em periódicos da Educação, com destaque para a Revista Brasileira de Educação Especial. Sugere-se a necessidade de maior divulgação dessas práticas em revistas propriamente da Psicologia, considerando que o psicólogo necessita, cada mais, informar-se acerca dessa nova demanda e dos trabalhos que estáo sendo realizados na atualidade.

Numa análise mais pormenorizada acerca das intervençóes realizadas, percebeu-se que o público-alvo atendido variou bastante, tendo aparente prioridade a pessoa com deficiência e os professores. Todavia, dentre as deficiências atendidas, verificou-se que as intervençôes foram mais focais (Autismo, Síndrome de Down, Paralisia Cerebral e Deficiência Mental), náo tendo sido observados relatos de experiência mais abrangentes. Além disso, muitos trabalhos pautaram-se mais em reflexóes teóricas acerca da temática que propriamente na indicação de diretrizes práticas. Vale ressaltar que, dentre o universo pesquisado com as palavras-chave Educação Inclusiva e Intervenção, não se encontrou nenhum trabalho que apresentasse um modelo interventivo mais amplo, que pudesse direcionar o ambiente escolar para as muitas possibilidades de intervenção junto às diversas NEE, especialmente com contribuiçôes do profissional psicólogo. Frente a isso, pesquisas e publicaçóes com esse propósito são urgentes e necessárias, para efeito de orientação às práticas escolares para a Educação Inclusiva nas diversas realidades educacionais do país. 
Ainda no tocante às lacunas observadas, percebe-se que os trabalhos analisados focaram como público-alvo alunos de 04 a 16 anos e acima de 16, sendo considerados nesse último intervalo os professores e pais. Verifica-se, portanto, que há temas ainda a serem explorados, uma vez que os alunos do Ensino Médio e Ensino Superior deveriam ser igualmente contemplados nessas pesquisas.

Face ao exposto, ficou evidente a carência de produção científica sobre essa prática, que demanda atenção urgente de pesquisadores e profissionais que tenham conhecimentos a compartilhar, especialmente no campo da Psicologia. Que o presente trabalho sirva para sensibilizá-los a respeito.

\section{Referências}

CRUZ, G. C. et al. Formação continuada de professores inseridos em contextos educacionais inclusivos. Revista Educar em Revista, n. 42, out./dez., 2011.

DECLARAÇÃO de Salamanca e enquadramento da ação. Disponível em: <http://redeinclusao.web.ua.pt/files/ fl_9.pdf $>$. Acesso em: 02 maio de 2014. (07 a 10/06/1994).

FABRICIO, N. M. C.; CANTOS, P. V. V. Diagnóstico-intervenção-perspectivas: atuaçấo da escola inclusiva. Revista Construçáo Psicopedagógica, v. 19, n. 19, p. 5-6, 2011.

FERREIRA, et al. Arte, formação de professores e inclusão escolar: possibilidades de atuação do psicólogo em contextos educacionais. Revista Cadernos de Psicopedagogia, v. 7, n. 13, 2009.

FREITAS, M. C.; MENDES, E. G. Análise funcional de comportamentos inadequados e inclusão: uma contribuição à formação de educadores. Revista Temas em Psicologia v. 16, n. 02, p. 261-271, 2008. Disponível em: <http://tinyurl.com/qefmp7y . Acesso em: 02 maio, 2014.

GOMES, C. G. S. Autismo e ensino de habilidades acadêmicas: adição e subtração. Revista Brasileira de Educaçáo Especial, v. 13, n. 3, set./dez., 2007.

(IBGE) - Instituto Brasileiro de Geografia e Estatística. Censo Demográfico 2000. Disponível em: <http:// www.ibge.gov.br/home/presidencia/noticias/27062003censo.shtm>. Acesso em: 02 maio, 2014.

JURDI, A.P.S.; AMIRALIAN, M.L.T.M. A inclusão escolar de alunos com deficiência mental: uma proposta de intervenção do terapeuta ocupacional no cotidiano escolar. Revista Estudos de Psicologia (Campinas), v. 23, n. 2, p. 191-202, 2006.

LDB - Lei de Diretrizes e Bases da Educaçáo (9394/96). Disponível em: <http://portal.mec.gov.br/seesp/ arquivos/pdf/lei9394_ldbn2.pdf>. Acesso em: 02 maio, 2014.

LEI N. 8069 de 13 de julho de 1990. Disponível em: <http://portal.mec.gov.br/seesp/arquivos/pdf/lei8069_01. pdf>. Acesso em: 02 maio, 2014.

LEMOS, E. L. M. D.; SALOMĀO, N. M. R.; RAMOS, C. S. A. Inclusão de crianças autistas: um estudo sobre interaçôes sociais no contexto escolar. Marilia. Revista Brasileira de Educaçáo Especial, v. 20, n. 1. jan./ mar., 2014.

LOPES, S. A. Consideraçóes sobre a terminologia alunos com necessidades educacionais especiais. Revista Educaçáo Especial, v. 27, n. 50, set./dez., 2014.

MACHADO, A. C.; ALMEIDA, M. A. Parceria no contexto escolar: uma experiência de ensino colaborativo para educação inclusiva. São Paulo. Revista Psicopedagogia, v. 27, n. 84, 2010.

MATTOS, L. K. ; NUERNBERG, A. H. A intervençáo do psicólogo em contextos de educação especial na grande Florianópolis. Marilia. Revista Brasileira de Educaçáo Especial, v. 16, n. 2. maio/ago., 2010.

NORONHA, E. G.; PINTO, C. L. Educaçáo Especial e Educaçăo Inclusiva: aproximaçôes e convergências. Disponível em: <http://www.catolicaonline.com.br/semanapedagogia/trabalhos_completos>. Acesso em: 17 out. 2014.

OMOTE, S. et al. Mudança de atitudes sociais em relação à inclusão. Revista Paideia (Ribeirão Preto), v. 15, n. 32, set./dez., 2005.

POLÍTICA Nacional de Educação Inclusiva. Disponível em: <http://portal.mec.gov.br/seesp/arquivos/pdf/politica.pdf>. Acesso em: 02 mai., 2014. 
ROCHA, M. L. Inclusão ou exclusão? Produção de subjetividade nas práticas de formação. Revista Psicologia em Estudo, v. 13, n.3, p. 477-484, 2008.

ROLFSEN, A. B.; MARTINEZ, C. M. S. Programa de intervenção para pais de crianças com dificuldades de aprendizagem: um estudo preliminar. Revista Paideia (Ribeirão Preto), v. 18, n. 39, 2008.

SILVA, A. M.; MENDES, E. G. Psicologia e inclusão escolar: novas possibilidades de intervir preventivamente sobre problemas comportamentais. Revista Brasileira de Educaçáo Especial, v. 18, n.1, jan./mar., 2012.

SOUZA, G. C.; PICH, S. A reorientação da ação pedagógica na Educação Física sob a perspectiva da inclusão: a pesquisa-ação como caminho. Revista Movimento (Porto Alegre), v. 19, n. 3, p. 149-169, 2013.

\section{Correspondência}

Maria das Graças Soares Siqueira - Av. Ivo do Prado n. 210, Idifício Ivo do Prado, Apt. 401, Bairro Centro, CEP: 49010-050 - Aracaju, Sergipe, Brasil.

E-mail: gal-ceme@hotmail.com

Recebido em 03 de novembro de 2014

Aprovado em 02 de março de 2015 